\title{
Corrigendum: Low-Temperature Adaptation of the Snow Alga Chlamydomonas nivalis Is Associated With the Photosynthetic System Regulatory Process
}

OPEN ACCESS

Approved by:

Frontiers Editorial Office,

Frontiers Media SA, Switzerland

*Correspondence:

Qiang Wang

wangqiang@henu.edu.cn;

wangqiang@ihb.ac.cn

Specialty section

This article was submitted to

Microbiotechnology,

a section of the journal

Frontiers in Microbiology

Received: 22 April 2021

Accepted: 22 April 2021

Published: 07 May 2021

Citation:

Zheng Y, Xue C, Chen $\mathrm{H}, \mathrm{He} \mathrm{C}$ and

Wang Q (2021) Corrigendum:

Low-Temperature Adaptation of the Snow Alga Chlamydomonas nivalis is

Associated With the Photosynthetic

System Regulatory Process.

Front. Microbiol. 12:698706

doi: 10.3389/fmicb.2021.698706
Yanli Zheng ${ }^{1,2}$, Chunling Xue ${ }^{1,2}$, Hui Chen ${ }^{1,3}$, Chenliu $\mathrm{He}^{1}$ and Qiang Wang ${ }^{3,4 *}$

${ }^{1}$ Key Laboratory of Algal Biology, Institute of Hydrobiology, Chinese Academy of Sciences, Wuhan, China, ${ }^{2}$ University of Chinese Academy of Sciences, Beijing, China, ${ }^{3}$ State Key Laboratory of Crop Stress Adaptation and Improvement, School of Life Sciences, Henan University, Kaifeng, China, ${ }^{4}$ Innovation Academy for Seed Design, Chinese Academy of Sciences, Wuhan, China

Keywords: antioxidant enzymes, Chlamydomonas nivalis, cyclic electron transfer, low temperature, photosynthesis

\section{A Corrigendum on}

Low-Temperature Adaptation of the Snow Alga Chlamydomonas nivalis Is Associated With the Photosynthetic System Regulatory Process

by Zheng, Y., Xue, C., Chen, H., He, C., and Wang, Q. (2020). Front. Microbiol. 11:1233. doi: $10.3389 /$ fmicb.2020.01233

In the original article, there was an error in affiliation 2 as published. Instead of University of the Chinese Academy of Sciences, Beijing, China, it should be University of Chinese Academy of Sciences, Beijing, China.

The authors apologize for this error and state that this does not change the scientific conclusions of the article in any way. The original article has been updated.

Copyright (c) 2021 Zheng, Xue, Chen, He and Wang. This is an open-access article distributed under the terms of the Creative Commons Attribution License (CC BY). The use, distribution or reproduction in other forums is permitted, provided the original author(s) and the copyright owner(s) are credited and that the original publication in this journal is cited, in accordance with accepted academic practice. No use, distribution or reproduction is permitted which does not comply with these terms. 